\title{
FORMULATION AND EVALUATION OF ANTIFUNGAL PRONIOSOMAL GEL FOR ORAL CANDIDIASIS
}

\author{
Rao Monica *, Kamble Priyanka \\ Department of Pharmaceutics, AISSMS College of Pharmacy, near RTO, Kennedy Road, Pune-411001, India
}

\begin{abstract}
Fluconazole is a synthetic antifungal drug, belonging to triazole group and mostly used to treat oral candidiasis caused by the yeast Candida albicans. Fluconazole commercially available in tablets that offer poor bioavailability, due to hepatic first pass effect and gastric instability leads to frequent dosing. Buccal drug delivery can bypass such problems of tablet and leads to increase in bioavailability. Due to low molecular weight, fluconazole can suitably administered by buccal route, hence local and targeted action can achieve. The present study was conducted to develop proniosomal gel of fluconazole by coacervation phase separation method using Span 20, cholesterol, soya lecithin, ethanol and aqueous vehicle. Based on preliminary studies surfactant and aqueous vehicle was selected. The Box Behnken design was employed to optimized proniosomes by evaluating responses like entrapment efficiency, vesicle size and drug release. The optimized proniosomes were evaluated with entrapment efficiency $(96.83 \%)$, vesicle size $(2 \mu \mathrm{m})$, in vitro drug release $85.66 \%(3 \mathrm{~h})$ and ex vivo mucosal permeation $(85.67 \%)$ with flux $\left(394.09 \mu \mathrm{g} / \mathrm{cm}^{2} \mathrm{~h}\right)$. The optimized proniosomes were incorporated into $2 \% \mathrm{w} / \mathrm{w}$ Carbopol gel 934 (1:1) to obtain proniosomal gel. This optimized proniosomal gel was found with good viscosity, good spreadability and adhesiveness, also it shows maximum drug release and permeation as compared to plain gel of fluconazole. In microbiological studies, optimized formulation shows the maximum inhibitory effect as compared to plain gel of drug, which concluded that optimized proniosomal gel exerted local and targeted buccal delivery with good fungistatic effect than plain gel of fluconazole against Candida albicans.
\end{abstract}

Keywords: proniosomal gel, oral candidiasis, fluconazole, mucoadhesion, Candida albicans.

Article Info: Received 21 May, 2018; Review Completed 09 July 2018; Accepted 10 July 2018; Available online 15 July 2018

\section{Cite this article as:}

Rao M, Kamble P, Formulation and evaluation of antifungal proniosomal gel for oral candidiasis, Journal of Drug Delivery and Therapeutics. 2018; 8(4):291-301 DOI: http://dx.doi.org/10.22270/jddt.v8i4.1793

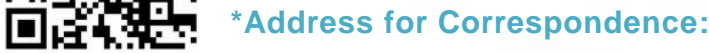

Dr Monica RP Rao, Department of Pharmaceutics, AISSMS College of Pharmacy, near RTO, Kennedy Road, Pune, Maharashtra411001, India

\section{INTRODUCTION}

Oral candidiasis, also known as oral thrush or oropharyngeal candidiasis is one of the most common human fungal infections of the oral cavity seen in all stages of life. The infection is caused by Candida albicans, which is dimorphic fungal organism that is typically present in the oral cavity ${ }^{1}$. Candida albicans is commensal organism and is a part of the normal oral flora in about $30 \%-50 \%$ of the population, a small amount of this fungus normally lives in the mouth without causing harm. However, when the fungus begins to grow uncontrollably, an infection can develop ${ }^{2}$. Oral candidiasis can be a frequent and significant source of oral discomfort, pain and aversion to food ${ }^{3}$.This infection is mostly seen in persons with human immunodeficiency virus (HIV) and cancer, because of their weak immunity ${ }^{4}$.

Proniosomal gel preparations are semisolid liquid crystal products of non-ionic surfactants prepared by dissolving the surfactant in a minimum amount of organic solvent (ethanol) and aqueous phase (water). These structures are liquid crystalline compact niosomes hybrids that can be converted into niosomes immediately upon hydration. Proniosomal gel in buccal delivery doesn't require hydration prior to application. Instead these can be applied as such or loaded on a gel base ${ }^{5}$.The gel base helps in adhesion of the formulation to the buccal mucosa. Proniosomal gel offers a great potential to 
reduce the side effects of drugs and increase therapeutic effectiveness. Proniosomal gel can entrap both hydrophilic and hydrophobic drugs. These are generally present in transparent, translucent or yellow semisolid gel texture, which Makes them physically stable during storage and transport (S.H. Abd El-alim; 2014) ${ }^{6}$. Fluconazole (FLZ) is a synthetic antifungal agent, belonging to triazole group and most commonly used to treat oral fungal infections, such as oral candidiasis caused by pathogenic fungi, like Candida albicans ${ }^{7}$. FLZ commercially available as conventional tablets and capsules that offer poor bioavailability of the drug due to extensive hepatic first pass metabolism and gastric instability leading to frequent dosing ${ }^{8}$. Drug delivery by the buccal route can bypass the hepatic first pass effect and minimize the degradation in the gastric environment, thereby affecting enhancement in bioavailability. FLZ has $\log \mathrm{P}$ value of 0.4 and its low molecular weight Make it a suitable candidate for administration by the buccal route ${ }^{9}$.

The present study was conducted to develop a proniosomal gel of FLZ by coacervation phase separation method using Span 20, cholesterol, soya lecithin and solvents like ethanol and distilled water. Optimization was carried out using 3 independent variables at 2 different levels were selected using Box Behnken design. The independent variables included Span 20, distilled water and soya lecithin. The vesicle size, percent drug release and entrapment efficiency were selected as responses and finally optimized proniosomes was characterized by vesicle size, entrapment efficiency, in vitro drug release studies, ex vivo mucosal permeation studies. After incorporating it into $2 \%$ Carbopol gel base $(1: 1)$, the final proniosomal gel was evaluated with viscosity, mucoadhesion and spreadability studies, in vitro drug release studies, ex vivo mucosal permeation studies, in vitro mucosal retention studies and microbiological studies.

\section{MATERIALS}

FLZ was gifted by Nulife Pharmaceuticals, Pune, India. Soya lecithin, cholesterol, Span 20 was purchased from S.D. Fine Pvt. Ltd Mumbai, ethanol AR was purchased from Loba chemicals Pvt. Ltd, Mumbai. All the reagents and solvents used were of analytical grade.

\section{METHODS}

\section{UV spectrophotometric analytical method:}

Weighed quantity (100 mg) of FLZ was added into methanol AR grade $(100 \mathrm{ml})$ in a volumetric flask. Different concentrations were prepared as 10, 20, 30, 40, $50 \mu \mathrm{g} / \mathrm{ml}$ by diluting the stock solution with methanol, and analysis was done at $260 \mathrm{~nm}$ by UV spectrophotometer (Jasco V-550, Japan) against methanol as a blank (Figure 1). The validation parameters such as precision (intra-day and inter-day precision), accuracy, limit of detection (LOD) and limit of quantification (LOQ) were studied ${ }^{10}$.

\section{Drug excipient compatibility studies:}

The compatibility of drug and excipients was checked by using Fourier Transform Infra-Red Spectrophotometer (JASCO FTIR-460+ spectrophotometer), for this the drug and excipients were kept in $1: 1$ ratio at $40^{\circ} \mathrm{C} \pm 75 \%$ relative humidity for 1 month to check any reaction which may take place between drug and excipients ${ }^{11}$.

\section{Preliminary Studies}

\section{Selection of surfactants and solvents:}

Trial batches (A1-A9) of drug loaded proniosomes were prepared by coacervation phase separation method using different combinations of surfactants and vehicles along with soya lecithin and cholesterol (Table 1). The surfactants that were studied included Span 20, Span 60, Span 80 and various vehicles included $0.1 \%$ aqueous glycerol solution, distilled water and phosphate buffer $\mathrm{pH}$ 6.8. Weighed quantity of FLZ, surfactant, soya lecithin and cholesterol was mixed with ethanol. The mixture was warmed in a water bath (Make: Metalab) at $40^{\circ} \mathrm{C}$ for $10 \mathrm{~min}$. Vehicle was then added to the mixture and further warmed to $40^{\circ} \mathrm{C}$ in water bath for about 10 min to obtain a clear solution. The mixture was allowed to cool to room temperature $25^{\circ} \mathrm{C}$ until the dispersion was converted to gel. The batches were evaluated for percent entrapment efficiency, percent drug release and percent drug permeation.

Table 1: Trial batches (A1-A9) to select surfactant and vehicles

\begin{tabular}{|c|c|c|c|c|c|c|c|c|c|c|}
\hline & $\begin{array}{c}\text { Drug } \\
(\mathbf{g})\end{array}$ & $\begin{array}{c}\text { Cholesterol } \\
(\mathbf{g})\end{array}$ & $\begin{array}{c}\text { Soya } \\
\text { lecithin } \\
(\mathbf{g})\end{array}$ & $\begin{array}{c}\text { Span } \\
\mathbf{2 0}(\mathbf{g})\end{array}$ & $\begin{array}{c}\text { Span } \\
\mathbf{6 0}(\mathbf{g})\end{array}$ & $\begin{array}{c}\text { Span } \\
\mathbf{8 0}(\mathbf{g})\end{array}$ & $\begin{array}{c}\text { distilled } \\
\text { water }(\mathbf{m l})\end{array}$ & $\begin{array}{c}\mathbf{0 . 1 \%} \\
\text { glycerol } \\
\text { Sol. }(\mathbf{m l})\end{array}$ & $\begin{array}{c}\text { Phos. } \\
\text { buffer } \mathbf{~ p H} \\
\mathbf{6 . 8}\end{array}$ & $\begin{array}{c}\text { Ethanol } \\
(\mathbf{m l})\end{array}$ \\
\hline A1 & 0.1 & 0.1 & 0.1 & - & - & 0.9 & 2.5 & - & - & 0.5 \\
\hline A2 & 0.1 & 0.1 & 0.1 & 0.9 & - & - & - & - & 2.5 & 0.5 \\
\hline A3 & 0.1 & 0.1 & 0.1 & - & - & 0.9 & - & 2.5 & - & 0.5 \\
\hline A4 & 0.1 & 0.1 & 0.1 & - & 0.9 & - & 2.5 & - & - & 0.5 \\
\hline A5 & 0.1 & 0.1 & 0.1 & 0.9 & - & - & 2.5 & - & & 0.5 \\
\hline A6 & 0.1 & 0.1 & 0.1 & 0.9 & - & - & - & 2.5 & & 0.5 \\
\hline A7 & 0.1 & 0.1 & 0.1 & - & 0.9 & - & - & - & 2.5 & 0.5 \\
\hline A8 & 0.1 & 0.1 & 0.1 & - & 0.9 & - & - & 2.5 & & 0.5 \\
\hline A9 & 0.1 & 0.1 & 0.1 & - & - & 0.9 & - & - & 2.5 & 0.5 \\
\hline
\end{tabular}




\section{Experimental Design}

Effect of 3 independent variables at 2 different levels on various responses was evaluated using Box-Behnken design. These independent variables included Span 20, distilled water and soya lecithin with percent entrapment efficiency, vesicle size and percent drug release $(\%$ release $3 \mathrm{~h}$ ), as responses. Based on 2 levels, 15 batches (F1- F15) were prepared by Design Expert Software (Design Expert 11, Stat-Ease and Minneapolis, MN). The optimized batch was selected on the basis of high entrapment efficiency; low vesicle size and high percent drug release (Table 3 ). The optimized batch of proniosomes was further incorporated into $2 \% \mathrm{w} / \mathrm{w}$ Carbopol gel 934. Briefly, required quantity of Carbopol 934 was mixed with distilled water and mixed using magnetic stirrer (Make: Remi, Model: 1MLH) at $50 \mathrm{rpm}$ till the Carbopol dissolved. To this solution, the optimised proniosomes was added in a 1:1 ratio with continuous stirring till a homogenous gel was obtained. This gel was subjected to further evaluation.

\section{Evaluation of Drug Loaded Proniosomes}

\section{Vesicle size:}

The mean vesicle size of all design batches was analyzed by Malvern zeta seizer (Model- NanoZS90) based on the principle of dynamic light scattering. The proniosomes (1 ml) were diluted with glycerine and the vesicle size was measured. $^{12}$

\section{Percent Entrapment Efficiency:}

Proniosomes $(0.1 \mathrm{~g})$ were diluted with $10 \mathrm{ml}$ of phosphate buffer $\mathrm{pH}$ 6.8. The aqueous dispersion was sonicated in a sonicator bath (Make-Labman, ModelLMUC-2) for $10 \mathrm{~min}$, followed by centrifugation (Make- REMI, Model- RM-12CBh) at 6,000 rpm at $20^{\circ} \mathrm{C}$ for $1 \mathrm{~h}$. The supernatant was collected and assayed by UV spectrophotometer for un-entrapped drug at 260 $\mathrm{nm}$. The percentage of drug encapsulation (\%EE) was calculated by the following equation: ${ }^{13}$

$\%$ Entrapment efficiency

$$
=\frac{\text { Total drug }- \text { Unetrapped drug }}{\text { Total drug }} \times 100
$$

In vitro drug release and ex vivo mucosal permeation study:

In vitro drug release study and ex vivo mucosal permeation study was performed using Franz diffusion cell (Make- Orchid Scientifics). In these studies two different membranes were used, such as cellophane membrane (Pall Life Sciences, India Pvt. Ltd.) for in vitro drug release study and fresh oral goat mucosa for mucosal permeation study. The cellophane membrane was soaked for $24 \mathrm{~h}$ prior to diffusion study in phosphate buffer $\mathrm{pH}$ 6.8. The proniosomes $(300 \mathrm{mg})$ containing 5 mg FLZ was placed in the donor compartment. Both receptor and donor compartment consisted of phosphate buffer pH 6.8 at a temperature of $37 \pm 2{ }^{\circ} \mathrm{C}$ under constant magnetic stirring for $3 \mathrm{~h}$. Aliquots of $1 \mathrm{ml}$ were withdrawn every half hour from receptor compartment and replaced with equal volume of diffusion media to maintain constant receptor phase volume. The samples were suitably diluted and assayed for drug content using
UV spectrophotometer at $260 \mathrm{~nm}$. From the total drug content cumulative percent drug release in $3 \mathrm{~h}$ and permeation coefficient was calculated. ${ }^{14,15}$

\section{Drug content:}

The proniosomes $(0.1 \mathrm{~g})$ were diluted with $10 \mathrm{ml}$ of phosphate buffer $\mathrm{pH}$ 6.8, this dispersion was sonicated (Make-Labman, Model-LMUC-2) for $10 \mathrm{~min}$ at $30^{\circ} \mathrm{C}$ and absorbance was measured at $260 \mathrm{~nm}$. The total drug content was calculated by the following equation: ${ }^{16,17}$

$$
\text { Drug content }=\frac{\text { Theoretical yield }}{\text { Practical yield }} \times 100
$$

\section{Evaluation of Optimized Proniosomal Gel}

The optimized proniosomal gel was subjected to various studies such as viscosity, in vitro drug release and ex vivo mucosal permeation studies, in vitro mucosal retention studies, mucoadhesive strength and spreadability studies, microbiological studies, Stability studies.

The in vitro and ex vivo studies for optimized proniosomal gel and plain gel of FLZ were performed using same procedure as for proniosomes.

\section{In vitro mucosal retention studies:}

The amount of drug retained in buccal mucosa was determined after permeation studies ( $3 \mathrm{~h}$ ), by washing the mucosa with methanol and homogenizing in presence of methanol using homogenizer (bio lab instruments bl244) at $4000 \mathrm{rpm}$ for $5 \mathrm{~min}$. the tissue dispersion was centrifuged (make- Remi, model- rm-12cbh) at 9000 rpm for $15 \mathrm{~min}$ and the supernatant was filtered through whatman filter paper $(0.45 \mu)$ for analysis of drug content by UV spectrophotometer at $260 \mathrm{~nm} .^{18}$

\section{Viscosity:}

Viscosity of proniosomal gel was determined using Brookfield viscometer (Make- Brookfield, Model- DV II + Pro viscometer) Spindle number 7 was attached to the viscometer and dipped it into flask containing proniosomal gel $(50 \mathrm{~g})$, parameters such as rpm and spindle number was set as (20 rpm, spindle no.7) and viscosity was recorded. ${ }^{19}$

\section{Mucoadhesive strength and spreadability of proniosomal gel:}

The mucoadhesive strength and spreadability of proniosomal gel was determined using Brookfield texture analyser (CT 100). Mucoadhesive strength of formulation was determined by measuring force required to detach mucous membrane from the formulation. Fresh goat buccal mucosa was attached to the upper probe of the instrument; $2 \mathrm{~g}$ of proniosomal gel was place in lower chamber. The upper probe was slowly moved downward to touch the surface of the proniosomal gel. A force required to ensuring intimate contact between the mucosa and proniosomal gel was recorded. The spreadability was determined by taking proniosomal gel in the cup of the texture analyser, previously aligned with the upper probe. The upper probe was slowly dipped into cup containing proniosomal gel. The spreadability of formulation was determined by 
measuring force required to spread the formulation. The hardness value of optimized proniosomal gel was recorded. ${ }^{20,21}$

\section{Microbiological evaluation:}

The microbiological studies were performing to determine the effect of proniosomal gel against Candida albicans, and were compared with the effect of plain gel containing FLZ and standard drug solution. For this study, $20 \mathrm{ml}$ of sterilized soya bean casein digest agar was poured into six petriplates and inoculated with Candida albicans (100 $\mu 1$ per plate) was poured in six sterilized petriplates and three cups of $5 \mathrm{~mm}$ diameter were made using sterile cork borer in each petriplate. Different concentrations of proniosomal gel formulation $(1.5 \mu \mathrm{g} / \mu \mathrm{l}, 3.12 \mu \mathrm{g} / \mu \mathrm{l}, 6.5 \mu \mathrm{g} / \mu \mathrm{l}, 12 \mu \mathrm{g} / \mu \mathrm{l}$ and $25 \mu \mathrm{g} / \mu \mathrm{l})$ were prepared in dimethyl sulfoxide (DMSO) and accurately $25 \mu \mathrm{l}$ of each dilution was transferred to cups in laminar air flow unit. Likewise same concentrations for plain gel and standard drug solution was prepared and transferred to cups aseptically. The prepared petriplates were maintained in refrigeration $\left(5^{\circ} \mathrm{C}\right)$ for 20 min for facilitating diffusion of the solutions in to the medium and then incubated at $37^{\circ} \mathrm{C}$ for $72 \mathrm{~h}$ in incubator (Make-VHS Electronics, Model-Bacteriological incubator). The diameter of zone of inhibition surrounding each of the wells was recorded. ${ }^{22,23,24}$

\section{Stability studies:}

Stability studies was carried out as per ICH guideline, by storing the optimized proniosomal gel at various temperature conditions like refrigeration on $\left(4^{\circ} \mathrm{C}\right)$, room temperature $\left(25^{\circ} \pm 0.5^{\circ} \mathrm{C}\right)$ and elevated temperature $\left(45^{\circ} \pm 0.5^{\circ} \mathrm{C}\right.$ and $\left.70 \% \mathrm{RH}\right)$ from a period of 1 month to 3 months. Drug content and variation in the average vesicle diameter were periodically monitored (after 1, 2 and 3 months). ${ }^{25}$

\section{RESULTS AND DISCUSSION}

\section{UV spectrophotometric Analytical Method:}

The calibration curve showed good linearity in the Beer's law limit of $10-50 \mu \mathrm{g} / \mathrm{ml}$ in methanol AR grade for FLZ with correlation coefficient $\left(\mathrm{r}^{2}\right)$ of 0.990 (Figure 1 ). The method was validated by different parameters which included precision (intra-day and inter-day precision), accuracy, limit of detection (LOD) and limit of quantification (LOQ). The percent relative standard deviation (\% RSD) values of interday and intraday precision were found to be 1.924 and 1.24275 for 10 $\mu \mathrm{g} / \mathrm{ml}$. The mean recovery $(\mathrm{n}=3)$ was found to be 94.2 $\%(\% \mathrm{RSD}=1.18)$ for the drug FLZ showing the accuracy of the method. Limit of detection (LOD) and limit of quantification (LOQ) was found to be $1.1 \mu \mathrm{g} / \mathrm{ml}$ and $3.33 \mu \mathrm{g} / \mathrm{ml}$.

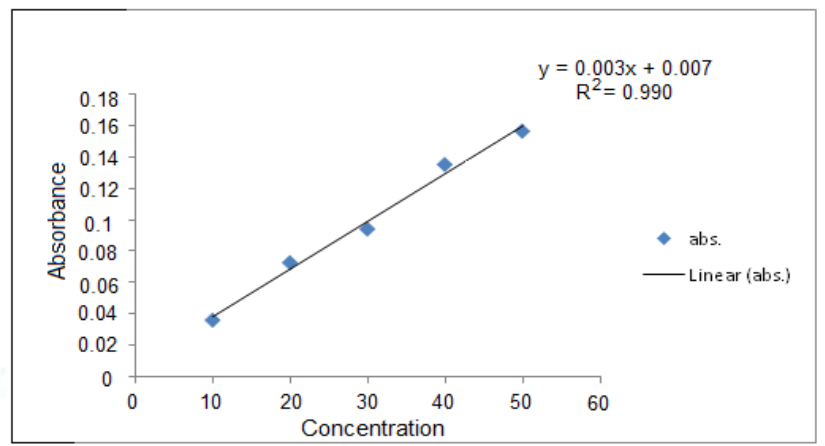

Figure 1: Calibration curve of Fluconazole analysed by UV-Vis Spectrophotometer

\section{Drug excipient compatibility studies:}

This study was carried out to check the interaction of drug and excipients. The characteristic IR peaks observed for FLZ include $\mathrm{OH}$ stretch, $\mathrm{CH}_{2}$ stretching, $\mathrm{CH}$ (aromatic stretching), $\mathrm{C}=\mathrm{N}$ stretch , $\mathrm{CH}$ (aromatic bending), and C-F stretch, at $3072.41 \mathrm{~cm}^{-1}, 1604.78 \mathrm{~cm}^{-}$ $1,1134.82 \mathrm{~cm}^{-1}$ and $901.28 \mathrm{~cm}^{-1}$. The FT-IR spectra of binary mixture drug with cholesterol, soya lecithin, Span 20 and Carbopol 934 showed no significant changes which indicated that there was no interaction between FLZ and other excipients.

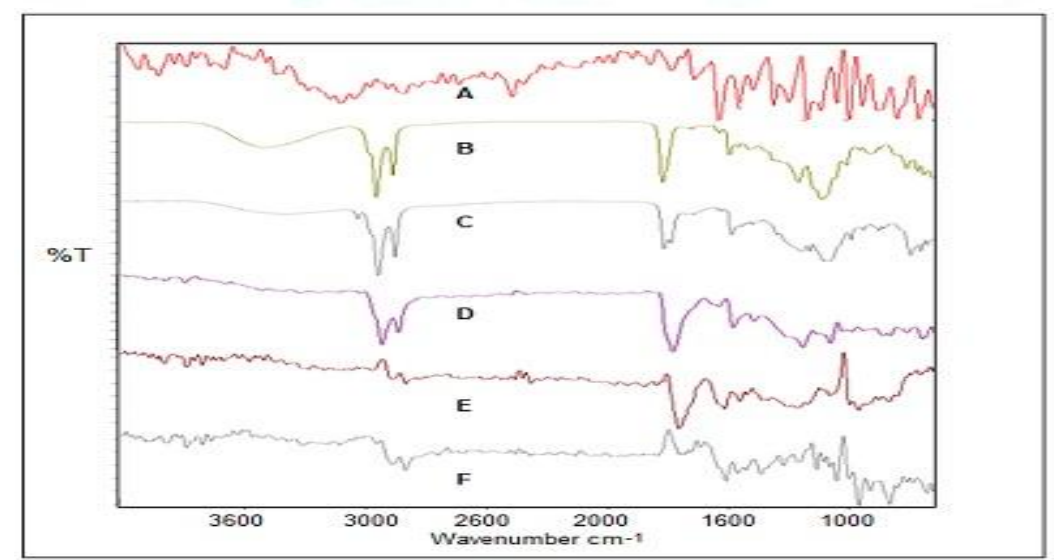

Figure 2: Compatibility studies of binary mixtures of drug and excipients (1:1 ratio) with A: Drug, B: cholesterol, C: Carbopol 934, D: Span 20, E: soya lecithin and F: physical mixture.

\section{Preliminary Studies}

\section{Selection of surfactant and vehicle:}

Trial batches of proniosomes were prepared to select surfactant and vehicle. Various surfactants that were studied included Span 20, Span 60, Span 80 and vehicles included $0.1 \%$ aqueous glycerol solution, distilled water and phosphate buffer $\mathrm{pH} 6.8$ along with other ingredients such as soya lecithin, cholesterol and ethanol. Total nine trial batches (A1-A9) were prepared 
and each batch was evaluated for percent entrapment efficiency, percent drug release and percent drug permeation. In all the batches, highest entrapment efficiency in each series of proniosomes were found in the following order i.e. Span $20>$ Span $60>$ Span 80 respectively. The entrapment efficiency of proniosomes depends on the value hydrophilic lipophilic balance (HLB) of surfactants. Surfactant with HLB value 8.6 gives highest entrapment. The entrapment efficiency decreases as the HLB value decreases from 8.6 to 1.7. (Gannu P. Kumar et. al, 2011). ${ }^{26}$

The percent drug release of proniosomes was depending on surfactants which formed less rigid and high permeable bilayer. The percent drug release of Proniosomes prepared with Span 20 was slower than those prepared using Span 60 and Span 80. Hence Span
20 was showing high percent release through the vesicles (Ruba Bnyan et. al, 2018). ${ }^{27}$

The mucosal permeation of proniosomes was depending on gel transition temperature of surfactants. The surfactant with higher transition temperature like Span 60 and Span 80 was penetrate slowly, the reason behind that, the surfactant needed higher temperature to formed disordered liquid crystalline state and to completely fluidized and hence they were less permeable. Whereas the contrary happen in case of surfactant with low transition temperature likes Span 20 and hence the permeation was increased (Thomas Litha et. al, 2011). ${ }^{28}$ The batch (A5) containing Span 20 (HLB 8.6) and distilled water showing high entrapment efficiency i.e. (96\%), high percent drug release $(84.30 \%)$ and high permeation rate, was selected for further studies. (Table 2)

Table 2: Results of trial batches for selection of vehicle and surfactant $\left({ }^{*} n=3\right.$, mean \pm SD)

\begin{tabular}{|c|l|c|c|c|}
\hline $\begin{array}{c}\text { Batch } \\
\text { No. }\end{array}$ & \multicolumn{1}{|c|}{ Batch } & $\begin{array}{c}\text { Entrapment efficiency } \\
(\boldsymbol{\%})\end{array}$ & $\begin{array}{c}* \text { Cummulative\% release } \\
\mathbf{( 3 ~ h )}\end{array}$ & $\begin{array}{c}* \text { Permeability } \\
(\mathbf{c m} / \mathbf{h r})\end{array}$ \\
\hline A1 & (Span 80+ distilled water) & $73.25 \pm 0.085$ & $78.16 \pm 0.584$ & $2.8822 \pm 0.099$ \\
\hline A2 & (Span 20+ Phosphate Buffer) & $96.83 \pm 1.012$ & $60.83 \pm 0.852$ & $3.4244 \pm 0.092$ \\
\hline A3 & (Span 80+ Glycerol Solution) & $68.63 \pm 3.052$ & $74.33 \pm 0.121$ & $3.2666 \pm 0.525$ \\
\hline A4 & (Span 60+ distilled water) & $80.09 \pm 0.948$ & $60.66 \pm 1.965$ & $1.6044 \pm 0.066$ \\
\hline A5 & (Span 20+ distilled water) & $96.04 \pm 2.078$ & $84.30 \pm 1.002$ & $3.6266 \pm 0.292$ \\
\hline A6 & (Span 20+ Glycerol Solution) & $93.77 \pm 1.179$ & $60.33 \pm 0.855$ & $2.9711 \pm 0.312$ \\
\hline A7 & (Span 60+ Phosphate Buffer) & $85.54 \pm 2.092$ & $59.00 \pm 0.254$ & $1.4244 \pm 0.051$ \\
\hline A8 & (Span 60+ Glycerol Solution) & $92.68 \pm 0.928$ & $57.05 \pm 0.145$ & $1.4577 \pm 0.072$ \\
\hline A9 & (Span 80+ Phosphate Buffer) & $74.83 \pm 1.064$ & $71.05 \pm 0.845$ & $2.9511 \pm 0.291$ \\
\hline
\end{tabular}

\section{Box Behnken Batches of Proniosomes}

Effect of 3 independent variables at 2 different levels on various responses was evaluated using Box-Behnken design. These independent variables included Span 20, distilled water and soya lecithin with percent entrapment efficiency, vesicle size and percent drug release $(\%$ release $3 \mathrm{~h}$ ), as responses. Based on 2 levels, 15 batches (F1-F15) were prepared by Design Expert Software (Design Expert 11, Stat-Ease, Minneapolis, MN).The measured responses were used to construct $3 \mathrm{D}$ response surface plot to establish the relationship between variables and their interaction. Analysis of variance (ANOVA) was used to validate the design

Table 3: Results of batches for optimization of formulation $(* n=3$, mean \pm SD)

\begin{tabular}{|c|c|c|c|c|c|c|c|}
\hline Std & Run & $\begin{array}{c}\text { A:Span } \\
\mathbf{2 0}\end{array}$ & $\begin{array}{c}\text { B:distilled } \\
\text { Water }\end{array}$ & $\begin{array}{c}\text { C:soya } \\
\text { Lecithin }\end{array}$ & $\begin{array}{c}\text { *Entrapment } \\
\text { efficiency }\end{array}$ & *Vesicle size & $\begin{array}{c}\text { Cumulative } \\
\text { release }\end{array}$ \\
\hline & & $\mathbf{g}$ & $\mathbf{m l}$ & $\mathbf{g}$ & $\mathbf{\%}$ & $\boldsymbol{\mu}$ & $\mathbf{\text { Rm }}$ \\
\hline F1 & 1 & 0.45 & 0.8 & 0.125 & $84.1 \pm 0.212$ & $3.5 \pm 0.586$ & $61.66 \pm 0.845$ \\
\hline F2 & 2 & 1.8 & 0.8 & 0.125 & $91.8 \pm 0.520$ & $3.0 \pm 0.255$ & $73.66 \pm 0.126$ \\
\hline F3 & 3 & 0.45 & 3.2 & 0.125 & $71.1 \pm 1.115$ & $4.0 \pm 0.754$ & $63.66 \pm 1.985$ \\
\hline F4 & 4 & 1.8 & 3.2 & 0.125 & $94.43 \pm 2.010$ & $3.2 \pm 0.295$ & $80.83 \pm 1.485$ \\
\hline F5 & 5 & 0.45 & 2 & 0.05 & $76.4 \pm 0.912$ & $5.2 \pm 1.845$ & $63.06 \pm 2.156$ \\
\hline F6 & 6 & 1.8 & 2 & 0.05 & $93.23 \pm 1.220$ & $2.6 \pm 0.211$ & $81.33 \pm 0.466$ \\
\hline F7 & 7 & 0.45 & 2 & 0.2 & $67.91 \pm 1.010$ & $3.1 \pm 0.120$ & $59.16 \pm 1.948$ \\
\hline F8 & 8 & 1.8 & 2 & 0.2 & $95.96 \pm 2.001$ & $4.2 \pm 0.369$ & $75.16 \pm 0.141$ \\
\hline F9 & 9 & 1.125 & 0.8 & 0.05 & $93.01 \pm 3.017$ & $7.1 \pm 2.101$ & $73.83 \pm 0.456$ \\
\hline F10 & 10 & 1.125 & 3.2 & 0.05 & $93.88 \pm 1.012$ & $3.8 \pm 0.148$ & $78.5 \pm 2.012$ \\
\hline F11 & 11 & 1.125 & 0.8 & 0.2 & $96.83 \pm 0.821$ & $3.0 \pm 0.456$ & $80.16 \pm 1.025$ \\
\hline F12 & 12 & 1.125 & 3.2 & 0.2 & $96.83 \pm 0.911$ & $2.1 \pm 0.210$ & $85.66 \pm 2.014$ \\
\hline F13 & 13 & 1.125 & 2 & 0.125 & $88.53 \pm 1.014$ & $6.6 \pm 1.142$ & $69.66 \pm 1.254$ \\
\hline F14 & 14 & 1.125 & 2 & 0.125 & $88.53 \pm 1.014$ & $6.6 \pm 3.152$ & $69.66 \pm 0.452$ \\
\hline F15 & 15 & 1.125 & 2 & 0.125 & $88.53 \pm 1.014$ & $6.6 \pm 1.294$ & $69.66 \pm 0.422$ \\
\hline
\end{tabular}




\section{Evaluation Parameters of Box-Behnken Batches}

\section{Percent entrapment efficiency: $\left(\mathbf{Y}_{1}\right)$}

Entrapment efficiency is one of the critical parameters that will affect the performance of the drug delivery form.

All the factorial batches (F1 to F15) were found to have significant effect on the entrapment efficiency $\left(\mathrm{Y}_{1}\right)$. The mean percent entrapment efficiency of all Box-Behnken batches was found to be in range $67.91 \%$ - $96.83 \%$ (table 3). The effect of amount of Span 20 (A) was found to be significant $(p<0.05)$, where the coefficient was found to be positive (Eq. 1). This implied that, an increase in amount of Span 20 (A) leads to increase in entrapment efficiency $\left(\mathrm{Y}_{1}\right)$ whereas all other factors were found to have an insignificant effect on entrapment efficiency $(p>0.05)$.
$\mathrm{Y} 1=88.53+12.05 \mathrm{~A}-1.63 \mathrm{~B}-1.99 \mathrm{C}+3.03 \mathrm{AB}+7.03$ AC -0.2175 BC $-9.13 \mathrm{~A}^{2}+6.85 \mathrm{~B}^{2}-0.2438 \mathrm{C}^{2}$

(Eq. 1).

Surfactant is the main component responsible for vesicle formation significantly increased the entrapment efficiency. This might be attributed to the increase in the number of formed proniosomes and consequently the volume of the hydrophobic bilayer domain, the available housing for entrapment FLZ hydrophobic drug. (Gagandeep Benipal, 2015) ${ }^{29}$. Besides this, proniosomes are capable of encapsulating both hydrophilic and hydrophobic drugs. Fluconazole, though having a low $\log \mathrm{P}(0.4)$ is poorly water soluble due to the presence of two triazole rings which impart significant basicity, to the molecule making it poorly water soluble. (Parthibarajan et al; 2013) ${ }^{30}$, (Ning et al; 2005) ${ }^{31}$.

Percent entrapment efficiency: $\left(\mathbf{Y}_{1}\right)$

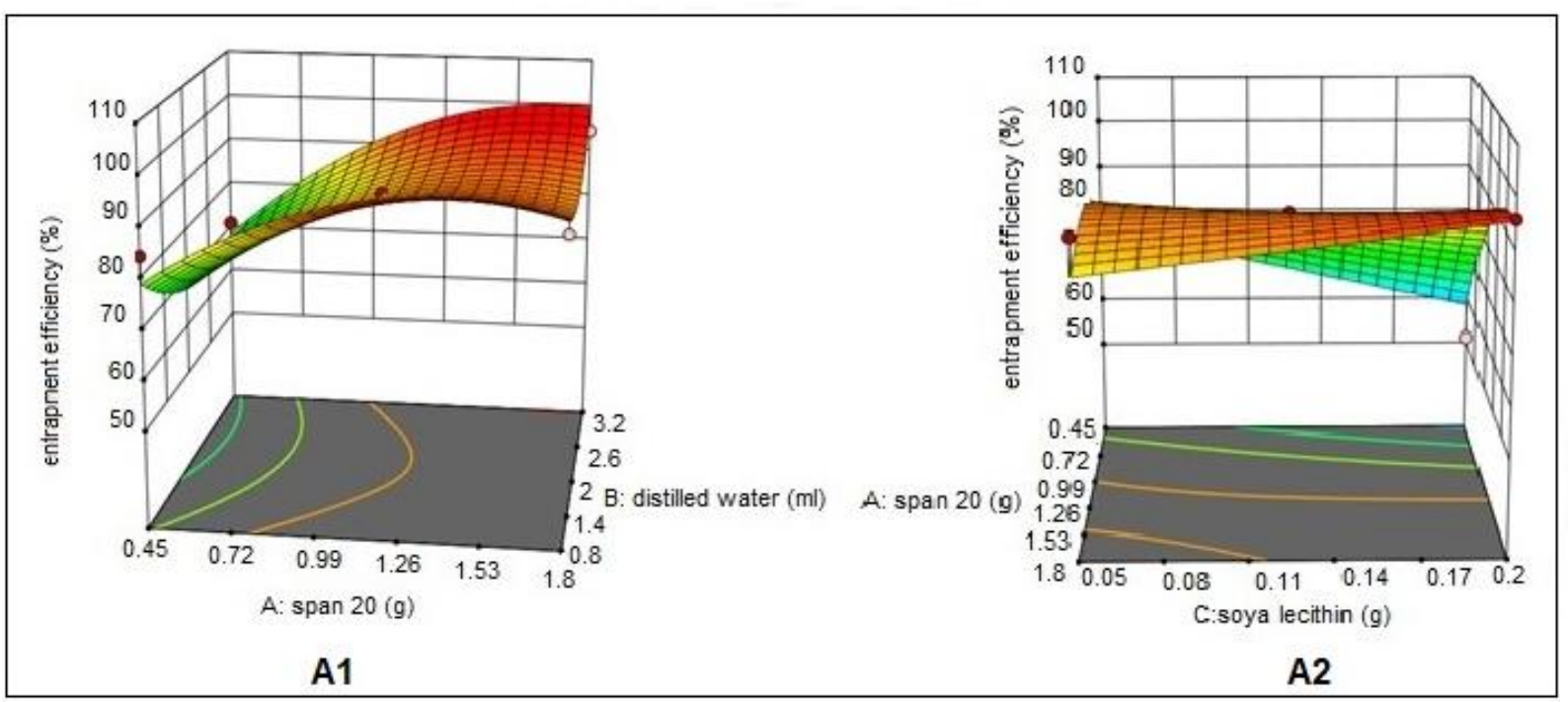

Figure 3: A1 and A2 represents the response surface curve plots for the entrapment efficiency $\left(\mathrm{Y}_{1)}\right.$

\section{Vesicle size: $\left(\mathbf{Y}_{2}\right)$}

Smaller vesicle size was advantageous to improve the penetration of vesicles into the mucosa.

The mean vesicle size $\left(\mathrm{Y}_{2}\right)$ of all factorial batches of proniosomes were found to be between $(2.1 \pm 0.214 \mu \mathrm{m})$ to $(7.1 \pm 2.101 \mu \mathrm{m})$. The effect of amount of Span 20 $\left(\mathrm{A}^{2}\right)$ was found to be significant $(\mathrm{p}<0.05)$ having a negative coefficient. This implied that, an increase in amount of Span 20 (A) leads to decrease in vesicle size $\left(\mathrm{Y}_{2}\right)$ it might be due to increasing surfactant concentration can also lead to an increase in charge, which in turn reduces vesicle aggregation and enhances the stability of the system ${ }^{29}$. The effect of volume of distilled water $\left(B^{2}\right)$ was found to be significant $(\mathrm{p}<$ $0.05)$, indicating decrease in vesicle size $\left(\mathrm{Y}_{2}\right)$ with increase in volume of distilled water (B). This is due to the volume of hydration medium affects the vesicle size (Gannu P. Kumar et. al; 2011) ${ }^{26}$. Whereas effect of all other factors was found to be non significant.

$\mathrm{Y} 2=+7.20-0.1625 \mathrm{~A}-0.6125 \mathrm{~B}-0.7750 \mathrm{C}+0.3000 \mathrm{AB}$ $+0.9250 \mathrm{AC}+0.5750 \mathrm{~B} \mathrm{C}-2.17 \mathrm{~A}^{2}-1.97 \mathrm{~B}^{2}-1.25 \mathrm{C}^{2}$ (Eq. 2). 


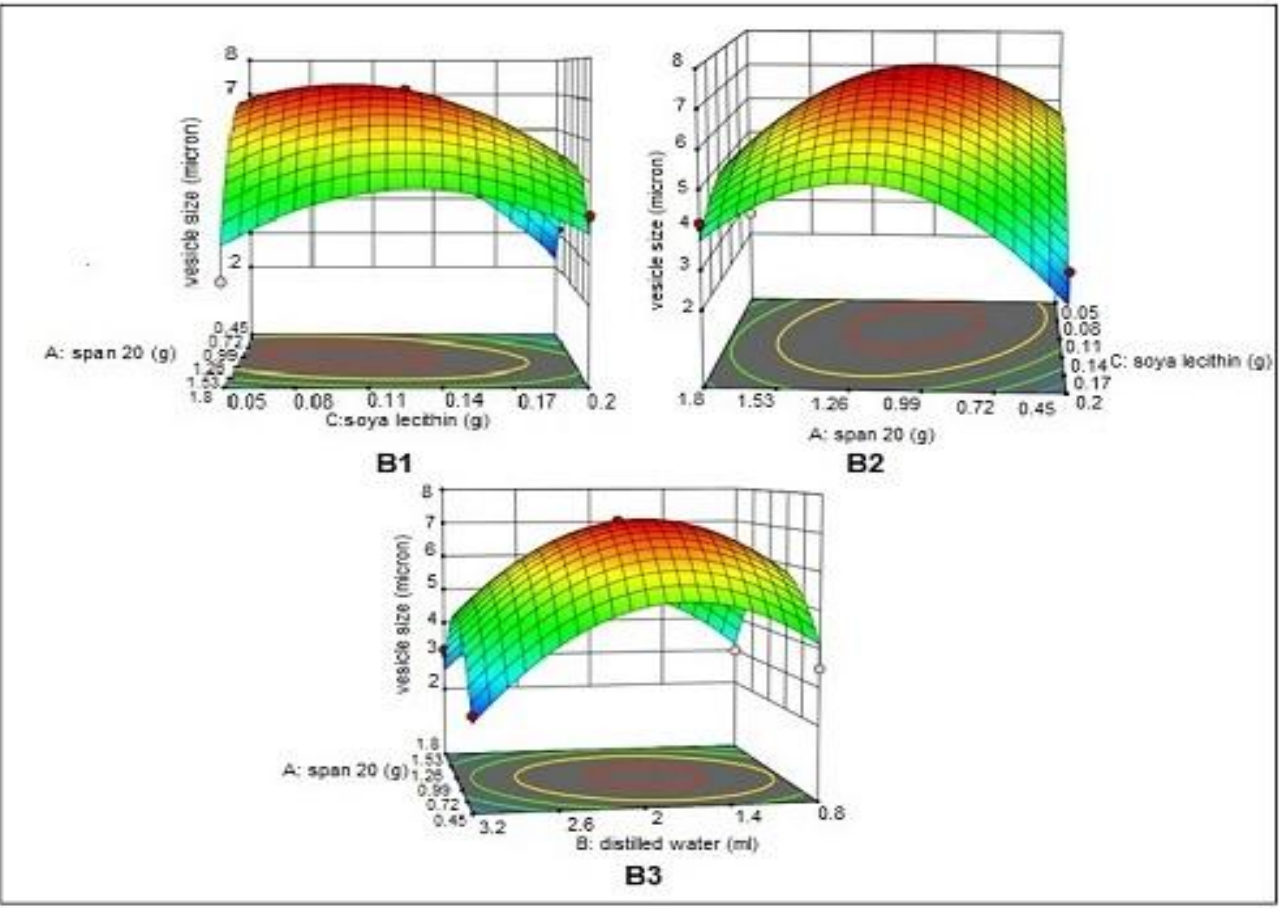

Figure 4: B1, B2 and B3 represents the response surface curve plots for the vesicle size $\left(\mathrm{Y}_{2}\right)$

\section{Percent drug release: $\left(\mathbf{Y}_{3}\right)$}

The percent drug release is one of the important characteristics affecting the performance of proniosomes.

The percent drug release $\left(\mathrm{Y}_{3}\right)$ of all factorial batches of proniosomes was found to be between $59-85 \%$ in $3 \mathrm{~h}$. The effect of amount of Span 20 (A) was found to be significant $(p<0.05)$ and the coefficient was found to be positive. This implied that, an increase in amount of
Span 20 (A) leads to an increase in percent drug release $\left(\mathrm{Y}_{3}\right.$ ) (Gagandeep Benipal; 2015) ${ }^{29}$. This is due to less rigidity and highly permeable bilayer formed by Span 20 (Ruba Bnyan et. al; 2018) ${ }^{27}$. Whereas effect of amount of all other factors was found to be non significant.

$\mathrm{Y} 3=+69.66+7.86 \mathrm{~A}+2.42 \mathrm{~B}+0.3500 \mathrm{C}+1.29 \mathrm{AB}-$ $0.4025 \mathrm{AC}+0.2075 \mathrm{BC}-4.71 \mathrm{~A}^{2}+5.00 \mathrm{~B}^{2}+4.87 \mathrm{C}^{2}$

(Eq. 3).
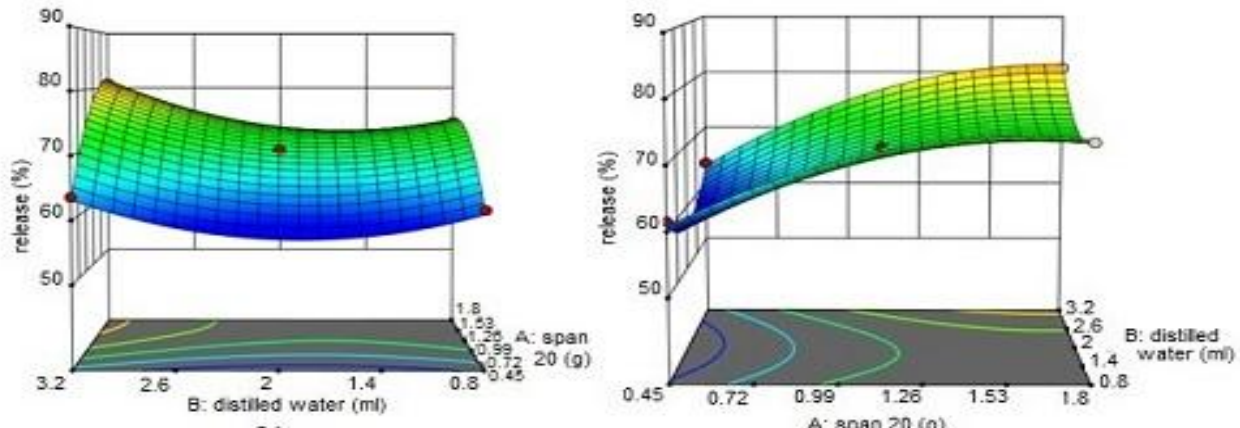

C1

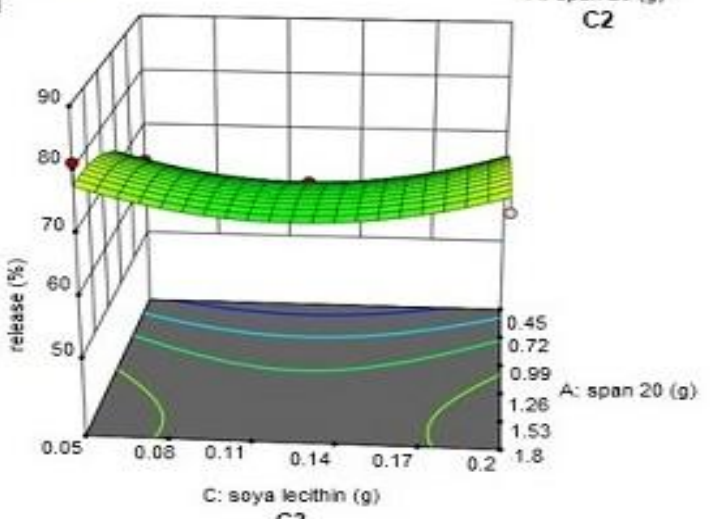

C3

Figure 5: $\mathrm{C} 1, \mathrm{C} 2$ and $\mathrm{C} 3$ represent the response surface curve plots for the $\%$ drug release $\left(\mathrm{Y}_{3}\right)$ 


\section{Selection of optimized formulation and validation studies}

Selection of optimized formulation for proniosomes were carried out, where the various trials were made to attain the goals like minimum vesicle size, maximum of entrapment efficiency and maximum of cumulative percent drug release. The optimized batch was chosen by numeric optimization using desirability function. The constraints set for numerical optimization of proniosomes included entrapment efficiency $\left(\mathrm{Y}_{1}>80 \%\right)$, vesicle size $\left(\mathrm{Y}_{2}<10 \mu \mathrm{m}\right)$ and cumulative percent drug release $\left(\mathrm{Y}_{3}>70 \%\right)$. Three different optimized batches of proniosomes generated by the software were prepared and evaluated to select one batch based on their desirability function. The selected optimized batch of proniosomes contained amount of Span 20 (1.125 g) (A), distilled water $(3.2 \mathrm{ml})$ (B) and soya lecithin $(0.2$ g)(C) exhibiting an entrapment efficiency of (96.1\%), vesicle size of $(2.6 \mu \mathrm{m})$, and cumulative percent drug release of $(85 \%)$ with desirability 1 . Thus, the formulation batch giving maximum entrapment efficiency $\left(\mathrm{Y}_{1}\right)$, minimum vesicle size $\left(\mathrm{Y}_{2}\right)$ and maximum cumulative percent drug release $\left(\mathrm{Y}_{3}\right)$ was chosen as the optimized batch.

Table 4: Box-Behnken design layout for optimization of proniosomes

\begin{tabular}{|c|c|c|c|c|}
\hline \multirow[t]{2}{*}{ Factors } & \multicolumn{3}{|c|}{ Levels } & \multirow[t]{2}{*}{ Responses } \\
\hline & -1 & 0 & +1 & \\
\hline Factor A: Span $20(\mathrm{~g})$ & 0.45 & 1.125 & 1.8 & \multirow{3}{*}{$\begin{array}{c}\text { \% Entrapment efficiency } \\
\text { Vesicle size } \\
\text { Percent drug release }\end{array}$} \\
\hline Factor B: distilled water $(\mathrm{ml})$ & 0.8 & 2 & 3.2 & \\
\hline Factor C: soya lecithin $(\mathrm{g})$ & 0.05 & 0.125 & 0.2 & \\
\hline
\end{tabular}

\section{Evaluation of Optimized Proniosomes}

Besides the three responses $\left(\mathrm{Y}_{1}, \mathrm{Y}_{2}\right.$ and $\left.\mathrm{Y}_{3}\right)$, the selected optimized batch of proniosomes were characterized by, ex vivo mucosal permeation and drug content. The drug content of optimized proniosomal gel was found to be $89 \%$.

\section{Ex vivo mucosal permeation studies:}

The ex vivo mucosal permeation studies (for $3 \mathrm{~h}$ ) of optimized proniosomes were carried out using fresh goat buccal mucosa as permeation membrane by Franz diffusion cell (Make- Orchid Scientifics) at $37^{\circ} \mathrm{C}$ in phosphate buffer $\mathrm{pH}$ 6.8. The percent drug permeated was found to be $85.67 \%$ in $3 \mathrm{~h}$ and flux was found to be $394.09 \mu \mathrm{g} / \mathrm{cm}^{2} \mathrm{~h}$ which shows high permeation of drug through the goat buccal mucosa. This is because lower the transition temperature better is the permeability as disordered liquid crystalline state is easily formed, resulting in a fluid vesicle membrane and hence higher permeation of drug. (Thomas Litha et. al; 2011). ${ }^{28}$

\section{Evaluation Optimized Proniosomal Gel}

In vitro drug release and ex vivo mucosal permeation study:-

The in vitro drug release studies (for $3 \mathrm{~h}$ ) of optimized proniosomal gel and plain gel of FLZ were carried out using cellophane membrane (Pall Life Sciences, India Pvt. Ltd.) by Franz diffusion cell (Make- Orchid sanctifies) at $37^{\circ} \mathrm{C}$ in phosphate buffer $\mathrm{pH}$ 6.8. The in vitro drug release from optimized proniosomal gel was found to be $77.08 \%$ in $3 \mathrm{~h}$ and for plain gel it was $51.04 \%$ in $3 \mathrm{~h}$. The percent drug release through the optimized proniosomal gel was $26.04 \%$ high due to presence of Span 20 in proniosomal gel.(fig 6) Span 20 is reported to form vesicles with relatively less rigidity and formed highly permeable bilayer (Ruba Bnyan et. al; $2018)^{27}$. This could explain the higher drug release. At the same time the solubility of FLZ is believed to be enhanced in the niosomes wherein the drug could possible be entrapped in the bilayers of the vesicles (Ruba Bnyan et. al; 2018) ${ }^{27}$.

The mucosal permeation of proniosomal gel through goat buccal mucosa was found to be $84.30 \%$ in $3 \mathrm{~h}$ and flux was found to be $387.8 \mu \mathrm{g} / \mathrm{cm}^{2}$.h, where as for plain gel it was $59.87 \%$ in $3 \mathrm{~h}$, and flux was found to be $283.10 \mu \mathrm{g} / \mathrm{cm}^{2}$.h (fig 6). This implied that proniosomal gel displayed nearly $25 \%$ higher release through cellophane membrane as well as high permeation (Thomas Litha et. al; 2011) ${ }^{28}$ of drug through the goat buccal mucosa as compared to plain gel of FLZ. Span 20 and soya lecithin in the proniosomes are responsible for the good permeability of FLZ. The transition temperature of the surfactant plays an important role in vesicle structure. Lower the transition temperature better is the permeability as disordered liquid crystalline state is easily formed, resulting in a fluid vesicle membrane and hence higher permeation of drug. Span 20 has a transition temperature (Thomas Litha et. al; 2011) ${ }^{28}$ hence it positively influences permeation of drug. Soya lecithin contains oleic and linoleic acid and hence it acts as a permeation enhancer as the double bond in the unsaturated fatty acids will cause the chain to bend by providing the conformational rotation to give cis/trans conformation. This will result in lower critical packing parameter and hence increased permeability, as the molecules are not tightly packed (Thomas Litha et. al; 2011). ${ }^{28}$ 


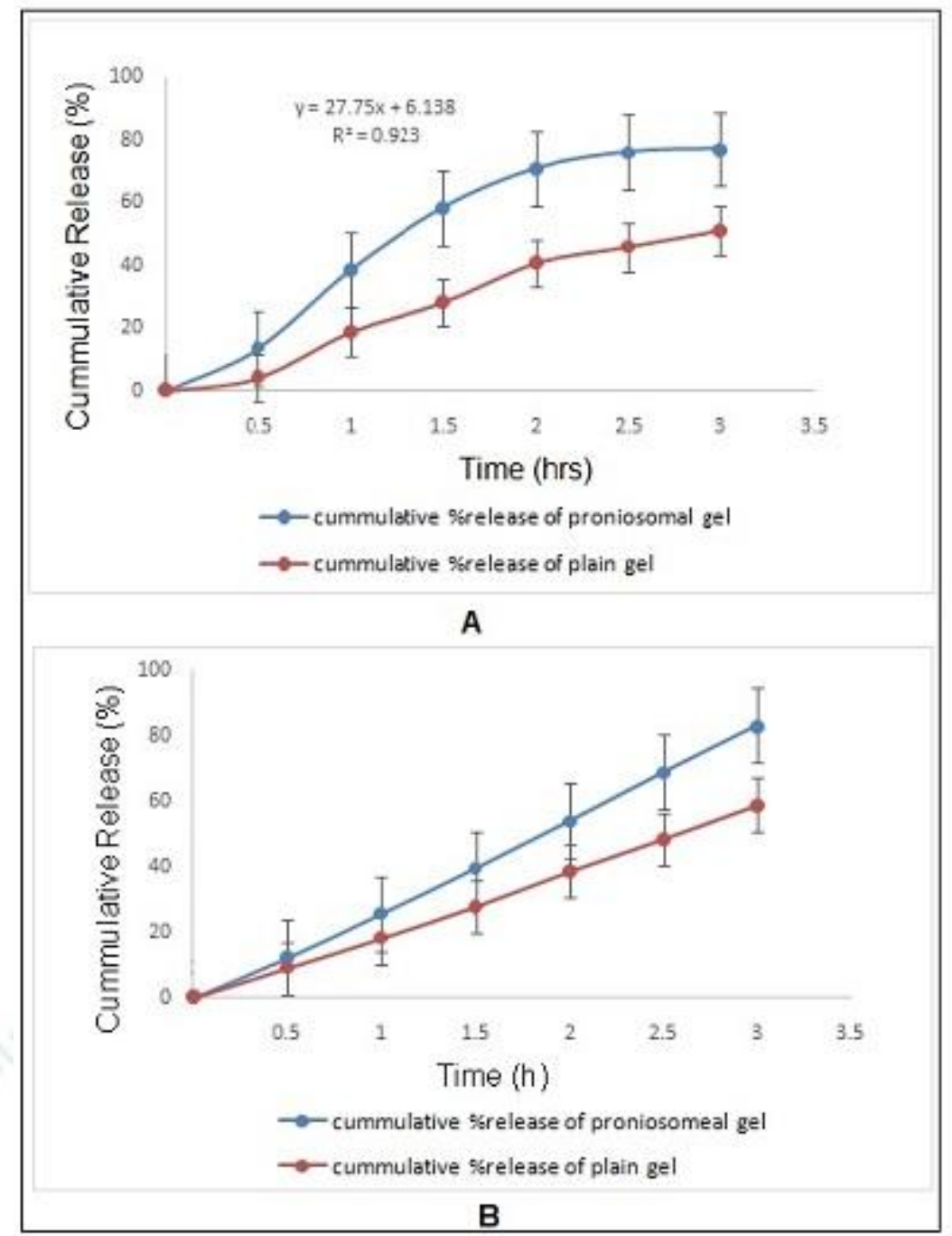

Figure 6: ' $\mathbf{A}$ ' represents the in vitro percent release of optimized proniosomal gel and plain gel of FLZ and 'B' represents the ex vivo permeation of optimised proniosomal gel and plain gel of FLZ

\section{In vitro mucosal retention studies:}

The amount of drug retained in buccal mucosa was determined after permeation studies (3h), and it was found to be $763 \mu \mathrm{g}$ at the end of $3 \mathrm{~h}$. This indicates that significant amount of drug is retained in the mucosal layers signifying continued therapeutic action even after $3 \mathrm{~h}$. Since oral candidiasis is a superficial infection, the higher drug retention is advantageous for the therapy. The molecular mass of FLZ is 306.3 daltons and it is reported that only small molecules with mass less than 100 daltons can cross the epithelial intercellular permeability barrier rapidly (Lee Martin et. al 2003) ${ }^{32}$. Thus we may presume that though proniosomes contain surfactants which are known to be penetration enhancers, FLZ, by virtue of its molecular size will remain in the superficial mucosal layers for longer duration of time. By comparing permeability data with retention studies, we may infer that soya lecithin and span 20 will facilitate penetration of drug through the fungal cell wall. It is also reported that despite the low porosity of fungal cell wall, different types of vesicles can travel through wall due to its deformable and viscoelastic properties (Louise Walker, et. al 2003). ${ }^{33}$

\section{Viscosity:}

Viscosity of optimized proniosomal gel (50 g), was determined using Brookfield viscometer $(20 \mathrm{rpm}$, spindle no.7) and viscosity was found to be $54733 \pm 550$ cps. The viscosity of $2 \%$ carbopol gel was found to be $32666 \pm 411 \mathrm{cps}$ whereas of the proniosomes, it was $1578 \pm 681 \mathrm{cps}$. Thus it is evident that the overall viscosity of the proniosomal gel is higher which will ensure prolonged residence of the formulation in the oral cavity.

\section{Mucoadhesive strength and spreadability of proniosomal gel:-}

The mucoadhesive strength and spreadability of proniosomal gel was determined using Brookfield texture analyser (CT 100) by measuring force required to detach mucous membrane from the formulation. Mucoadhesiveness of proniosomal gel was found to be $8.20 \mathrm{~g}$ which is adequate to ensure longer residence time in the oral cavity. Carbopol bind to oligosaccharide chain present in mucosal membrane, resulting in moderate bioadhesive force which enhanced gel strength. the spreadability of proniosomal gel were determined by texture analyser. The spreadability of 
proniosomal gel was determined by measuring force required to spread the formulation, which depends on hardness of proniosomal gel. As hardness increases spreadability of proniosomal gel decreases. The hardness value of optimized proniosomal gel was found to be 24.10 g. Spreadability is necessary to enable the formulation to cover as much mucosal area as possible and also to enable continued release of the drug.

\section{Microbiological evaluation:}

The microbiological assay for Candida albicans was carried out for optimized proniosomal gel and compared with plain gel formulation and pure drug solution. The diameter of zone of inhibition obtained with plain gel, optimized proniosomal gel and drug solution is shown in (figure 7$)$. The standard drug solution $(25 \mu \mathrm{g} / \mu \mathrm{l})$ showed zone of inhibition of $15 \mathrm{~mm}$ whereas the same was found to be $9 \mathrm{~mm}$ for plain gel containing $25 \mu \mathrm{g} / \mu \mathrm{ldrug}$. The zone of inhibition for optimized proniosomal gel was measured as $13 \mathrm{~mm}$. This indicated that optimized proniosomal gel showed good inhibitory effect against Candida albicans than that of the plain gel. These results confirm that the solubility of FLZ is enhanced in the proniosomes and that the drug is able to permeate through the vesicles and exert its fungistatic effect against Candida albicans, by inhibiting the cytochrome P-450 dependent enzyme lanosterol demethylase which is required for the conversion of lanosterol to ergosterol. Ergosterol is essential for fungal cell membrane integrity and function, resulting in inhibition of fungal growth (Mahipal Sinnollareddy, 2011). ${ }^{34}$

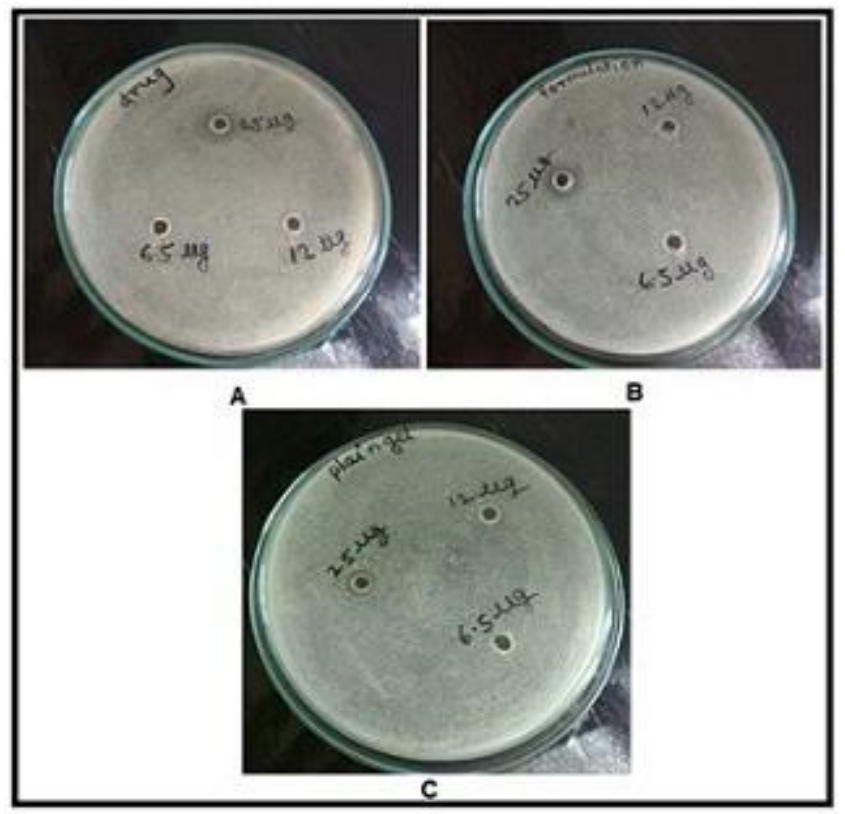

Figure 7: Zone of inhibition in drug solution (A), proniosomal gel formulation (B) and plain gel (C)

\section{Stability studies:}

The optimized batch of proniosomal gel was subjected to physical and chemical stability studies at $40^{\circ} \mathrm{C} \pm 75 \%$ $\mathrm{RH}$ for 3 months and evaluated at intervals of $0,1,2$ and 3 months. No significant differences in organoleptic properties were observed. Insignificant changes in FLZ content were seen. Thus, these studies assured that formulated optimized batch of proniosomal gel was stable up to 3 months.

Table 5: Drug content of optimized proniosomal gel for stability studies. ( $*^{n}=3$, mean \pm SD)

\begin{tabular}{|l|l|l|l|l|}
\hline Parameter & For 0 day & for 1st month & for $\mathbf{2}^{\text {nd }}$ month & for $3^{\text {rd }}$ month \\
\hline Drug content & $96.06 \pm 1.393$ & $96.00 \pm 1.10$ & $95.34 \pm 1.30$ & $94.65 \pm 1.218$ \\
\hline
\end{tabular}

\section{CONCLUSION}

Oral candidiasis, the most common fungal infection, caused by the yeast Candida albicans was treated with optimized proniosomal gel of FLZ, which was used for applied over buccal mucosa. Hence it showed good targeted and local action. The complete summary of present research work concluded that the optimized batch of proniosomal gel shows good storage stability, good fungicidal activity against Candida albicans as compared to plain gel of FLZ. Due to their vesicular content proniosomal gel gives high permeation rate, high percent drug release and highly retention of FLZ in buccal mucosa as compared to plain gel of FLZ.

\section{ACKNOWLEDGEMENT}

The authors would like to thank Dr. Ashwini Madgulkar Principal, AISSMS College of Pharmacy, Pune, Maharashtra, India for providing necessary facilities to carry out the research work. 


\section{REFERENCES}

1. Garcia-Cuesta C, Maria-Gracia, Sarrion-Pérez, Jose VB, Current treatment of oral candidiasis: A literature review, J Clin Exp Dent, 2014; 6(5):576-82

2. Singh A, Verma R, Oral candidiasis: An overview; J. Oral Maxillofac Pathology, 2014; 18:S81-S85.

3. Dangi YS, Soni ML, Oral Candidiasis: A Review, Int J Pharma and Pharmaceu Sci, 2010; 2:36-41.

4. Parkarwar CR, Qadri SM, Oral Candidiasis: A Review,World J Pharm Pharmaceu, 2017; 6:975-985.

5. Sandeep G, Vasavi Reddy D, Formulation and evaluation of fluconazole pro-niosomal gel for topical administration, J Applied Pharmaceu Sci, 2014; 4(07):098-104.

6. Mehta M, Garg M, Proniosomal Gel: A Promising Drug Carrier for Boswellic Acids, J Med Sci, 2015; 15(3):130-134.

7. Chandran CS, Chinnumol AV, Development And Characterisation Of Oral Soft Gel Containing Fluconazole Usp For The Treatment Of Oral Candidiasis, Int J Pharm, Chem Biol Sci, 2014; 4(4):985-993.

8. Kumar JR, Muralidharan S, Antifungal Agents: New Approach for Novel Delivery Systems, J Pharmaceu sci and research, 2014; 6(5):229-235.

9. Pathak K, Sharma V, Localization of fluconazole in oral cavity by preferential coating of buccoadhesive tablet for treatment of oral thrush, Int J Pharmaceu Investigation, 2016; 6:106-115.

10. Radha GV, Chowdary CHV, Formulation and Evaluation of Ornidazole Proniosomal Gel, Indo American J Pharmaceu Research, 2014; 4:2231-6876.

11. Reddy CMB, Spectrophotometric estimation of Fluconazole in pure drug and pharmaceutical formulation, Int J Sci \& Eng Research, 2012, 3, 1-7.

12. Abdelbary GA, Aburahma MH, Oro-dental mucoadhesive proniosomal gel formulation loaded with lornoxicam for management of dental pain, J Liposome Research, 2014; 1-15.

13. Kandasamy R, Veintramuthu S, Formulation and Optimization of Zidovudine Niosomes, AAPS Pharm Sci Tech, 2010; 11:1119-1127.

14. Benipal G, Design, Development and Evaluation of Proniosomal Gel of an Antifungal Drug - Ketoconazole, Int J Pharmaceu Sci Review and Research, 2015; 31(2):265-272.

15. Abd El-alim SH, Kassem AA, Proniosomes As A Novel Drug Carrier System For Buccal Delivery of Benzocaine, J Drug Del. Sci. Tech, 2014; 24(5):452-458.

16. Kumar K, Rai AK, Development and Evaluation of ProniosomeEncapsulated Curcumin for Transdermal Administration, Tropical J Pharmaceu Research December 2011; 10 (6):697-703.

17. Mittal S, Mittal A, Proniosomes as a Drug Carrier for Transdermal Delivery of Candesartan Cilexetil, Int $\mathbf{J}$ of Nano Studies \& Tech, 2013; 2:1-7.

18. Prasad V, Chaurasia S, performance evaluation of non ionic surfactant based tazarotene encapsulated proniosomal gel for the treatment of psoriasis, 2017; 79:168-176.
19. Reddy MC, Firoz S, Formulation And Evaluation Of Oral Thermorevesible In Situ Gel Containing Fluconazole, Int J Pharma Research \& Analysis, 2011, 1,15-20.

20. Basu S, Maity S, Preparation and Characterisation of Mucoadhesive Nasal Gel of Venlafaxine Hydrochloride for Treatment of Anxiety Disorders, Ind J Pharmaceu Sci, 2012; 428-433

21. Shukr MH, Metwally GF, Evaluation of Topical Gel Bases Formulated with Various Essential Oils for Antibacterial Activity against Methicillin-Resistant Staphylococcus Aureus, Tropical J Pharmaceu Research, 2013; 12(6):877-884.

22. Pankaj S, Rini T, Formulation and evaluation of proniosom based drug delivery system of the antifungal drug clotrimazole, Int J Pharmaceu sci nanotech, 2013; 6:1945-1951.

23. Basha BN, Prakasam K, Formulation and evaluation of Gel containing Fluconazole-Antifungal Agent, Int J Drug Development \& Research, 2011; 3(4):109-128.

24. Esma KAYA, Hatice O, Determination of the effect of fluconazole against Candida albicans and Candida glabrata by using microbroth kinetic assay, Turk J Med Sci, 2012; 42(2):325-328

25. Lather V; Sharma D et.al; Proniosomal gel-mediated Transdermal Delivery Of Bromocriptine: In Vitro And Ex Vivo Evaluation; J Exp Nano sci; 2016; 11:1044-1057.

26. Kumar GP, Rajeshwarrao P, Nonionic surfactant vesicular systems for effective drug delivery an overview; Acta Pharmaceutica Sinica B , 2011; 1(4):208-219.

27. Bnyan R, Surfactant effects on lipid-based vesicles properties, J Pharmaceu Sci, 2018; 1-29

28. Thomas L, provesicular niosomes gel: a novel absorption modulator for transdermal delivery, int. j. drug dev. \& res, 2011; 3(3):58-69.

29. Benipal G, Design, Development and Evaluation of Proniosomal Gel of an Antifungal Drug - Ketoconazole, Int J Pharmaceu Sci Review and Research, 2015; 31(2):265-272.

30. Parthibarajan R, Design and in vitro evaluation of voriconazole niosomes, Int J pharma and pharmaceu sci, 2013; 5:3604-611.

31. Ning M, Guo Y; Preparation, in vitro and in vivo evaluation of liposomal/niosomal gel delivery systems for clotrimazole, Drug Development and Industrial Pharma, 2005; 31:375-383.

32. Lee Martin, Sustained buccal delivery of the hydrophobic drug denbufylline using physically cross-linked palmitoyl glycol chitosan hydrogels, European Journal of Pharmaceutics and Biopharmaceutics, 2003; 55:35-45.

33. Walker L, The Viscoelastic Properties of the Fungal Cell Wall Allow Traffic of AmBisome as Intact Liposome Vesicles, American society for microbiology, 2018; 9:1-15.

34. Sinnollareddy M, Pharmacokinetic evaluation of fluconazole in critically ill patients, Expert Opin. Drug Metab. Toxicol, 2011; 7(11):1431-1440. 